\title{
The Applied Research on BOT Mode about Urban Rail Transit Project
}

\author{
Weifang Li \\ School of Management, Wuhan University of Science and Technology, Wuhan, 430081, China \\ wustlwf @163.com
}

Keywords: Urban rail transit project; BOT mode; Construction; Operations management.

\begin{abstract}
The urban rail transit project has become one of the main infrastructure projects in China. As an important construction management mode, BOT mode has been used for the urban rail transit projects in China. There are some problems which bother BOT mode about urban rail transit project in recent years, so the applied research on BOT mode about urban rail transit project has very important realistic meaning for development and construction of infrastructure projects. Relevant theoretical foundations of are given first in the paper. Then according to the main problems of financing, construction and operation about BOT mode in urban rail transit project, the related countermeasures are put forward, such as absorbing private capital and foreign investment, strictly controlling the cost of construction by some means, changing the original management mode and exploring external benefit of urban rail transit project, and so on.
\end{abstract}

\section{Introduction}

With the booming economies, China's urbanized process is accelerating. Developing urban rail transit project is the most cost-effective scheme for solving the problems of urban traffic jams and the growing environmental pollution. As an important construction management mode, BOT mode has been used for the urban rail transit projects in China. Some problems are inevitably emerging in urban rail transit BOT project, so they are what we need to dissect and solve. So the applied research on BOT mode about urban rail transit project has very important realistic meaning for development and construction of infrastructure projects.

\section{Some Relevant Theoretical Foundations of BOT Mode about Urban Rail Transit Project}

The Connotation of Urban Rail Transit. Usually, rapid public transport and large volume of traffic with electric energy power and by wheel running mode is referred to as rail traffic [1]. Rail transit includes subway and light rail routes. As one type of vehicle, rail traffic plays an important role in urban passenger flow transportation. And rail transit is an important detection guideline of accelerating the urbanization process, developing rail transit can make the urban planning perfect.

The Connotation of BOT Mode. BOT mode (Build-Operate-Transfer) is the complete process from building to operating and transferring. After deciding to construct the project, the government grants the enterprise concession, the enterprise constructs the project during the concession period. After building, the enterprise gets profits through the project operation. At the end of the concession period, the enterprise transfers the project to the government for free [2].

The Operation Process of Carrying Out the BOT Mode. Generally speaking, the operation process of carrying out the BOT mode includes some key processes. (1) The project preparation. The government or the enterprise presents a tentative concept of the project. Through investigation and auditing, the government decides to construct the project, and uses the project models of BOT. (2) The project bidding. After deciding to construct the project, the government invites some enterprise to bid for the construct project. The government signs the contract with the bid winner. (3) The project building. The bid winner builds the project. The bid winner arranges funds, controls project's quality in time, cost and products' performance. (4) The project operating. After building the project, the project comes into the operation stage. During the concession period, the bid winner enterprise 
reasonable operates of the project to gets profits, and is in charge of maintenance. (5) The project transferring. At the end of the concession period, the enterprise transfers the project to the government for free. When the government accepts the project, there is systematic check for the normal operations of on later. This process is illustrated in Fig. 1

The government

The private institutions

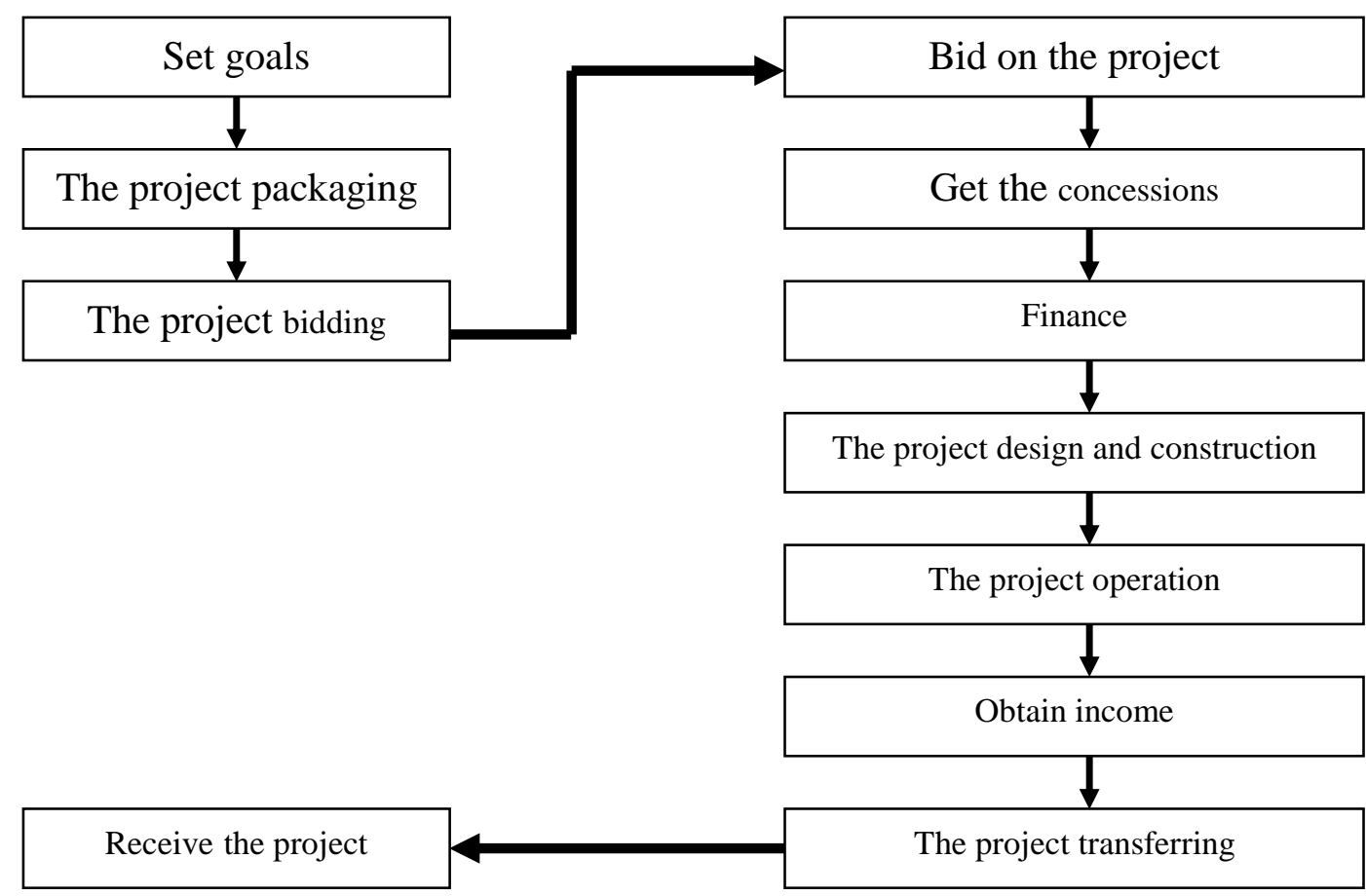

Figure 1. The flow chart of the BOT mode

\section{Some Problems Which Bother BOT Mode about Urban Rail Transit Project}

Some Problems in the Construction. There are some problems of the urban rail transit BOT project in the construction, including the following aspects.

The Funding Gap of Construction and Financing Difficulty. As the progress of urbanization accelerates, developing urban rail transit should be a priority for all in China. The first problem is funding gap of construction and financing difficulty. China is a developing country, financial support from the central government and the local government has done little to enormous investment of urban rail transit projects. The construction of the infrastructures is the only way to economic development in our present national conditions, financial support from the government has not kept up with the funding gap of construction[3]. Investment styles of large infrastructure projects are too simplex in China, infrastructure projects has been adopted the government investment in general. For example, in the construction of No. 1 Line of Shanghai subway, No. 2 Line of Shanghai subway, No. 1 Line of Guangzhou subway, foreign investments are induced, but the government investment took up most of the entire project portfolio.

The Cost of Construction is Still Difficult to Control. In the construction of the urban rail transit BOT project, cost controlling is always a thorny issue. The urban rail transit projects are rapidly developed at present in China, construction enterprises of rail transit projects are also rapidly growing, the enterprises competition become more and more fierce, so the enterprises cut down the bidding price to win the bidding. It is likely to lead to such consequences which the cost of construction is not enough to complete the urban rail transit BOT project well. On the other hand, the urban rail transit projects need to consume a lot of human, material, financial, the construction technology is complex 
and difficult, construction has longer period. All of those can lead to that the cost of construction is still difficult to control.

Some Problems in the Operation Stage. There are some problems of the urban rail transit BOT project in the operation stage, including the following aspects.

The Big Sunk Cost and Weak Profitability. The urban rail transit BOT project has features such as big sunk cost and weak profitability. Because investment of project is always high, the project can not be used in other ways after the completion. Meanwhile the project usually difficultly get enough profits in the initial operation, it always needs 20 years to recover the cost. This trait is less attractive to investors.

The Too Long Concession Duration and High Overall Operational Risks. Because of too Long concession duration, there are various risks in the operation stage. If the project can't reach the expected goal in the operation, the profit pattern of the project will be different from the real one, the project will can't get enough cash flow and be lead to loss. In addition, there are other risks in the operation stage, characterized by market risk, technical risk, financial risk, some natural disasters and force majeure. If the project involves foreign participants, there may be political risks and economic risks.

\section{Some Related Countermeasures of the BOT Mode about Urban Rail Transit Project}

Increasing Project Financing Channels. The practice of foreign urban rail transit projects shows that it is entirely feasible to introduce non-government capitals, it is premises that there are a lot of perfect laws and regulations. The government may introduce non-government capitals into the urban rail transit projects, and better insure the smooth development of the urban rail transit projects by laws and regulations, the government liability guarantees, government funds or subsidizes. Introducing foreign investment has also made the progress in China, but the whole scope of foreign investment is little and the level is not high. The government needs to formulate relevant policies and measures in our country. (1) Expanding the scale of introduction foreign capital. In comparison with our country, international financial institutions loans are longer and slow recovery. The difficulty of long cycle of urban rail transit projects construction may be solved by introduction foreign capital. (2) Issuing bonds abroad. Issuing bonds abroad is very common in the international marketplace. But it is very rare in the country. Issuing bonds abroad have some advantages such as big market capacity, the quicker financing speed, less distribution fee, compared with other sources of financing. (3) Issuing stock in international bourses. There have been previous attempts to construct urban rail transit projects in our country. As pilot projects, Guangshen Railway Company Limited was subsequently listed on the Hong Kong Stock Exchange and the New York stock exchange in 1996[4].

Serious Cost Control. Project cost control is especially important in the whole project cycle. $n$ order to realize the scientific cost control, we should adopt a series of measures such as cost projection, plan, accounting, analysis, assessment, etc. Cost control management covers the entire project, including former cost management, middle cost management and later cost management. In construction stage, project cost control is one of the measures to optimize construction scheme. For example, open surface method is used in Beijing's subway line 6 segment 07, two construction schemes were optimized. (1) To the selecting materials of profiled-steel prop. $200 * 200 \mathrm{H}$ beams were used instead of No 145 double I-beams. (2) Traffic guide scheme was optimized. The two schemes optimization reduced construction period of two months, saved more than 1500000 yuan.

Decreasing Operation Risks. Because the concession duration is too long and overall operational risks are high, we should study how to decrease operation risks. We can refer to Wuhan rail transit line 1 , it changed the situation of low profitability by changing the original management mode. (1) Route adjustment. Wuhan rail transit line 1 made a wise decision for route selection. Through route adjustment, the centrism between the site and the site become straight as possible, it is more conveniently and timesaving, which is beneficial to attract passengers and increase income. (2) Price making. There was little difference between ticket prices of Wuhan urban rail transit and ticket prices 
of Beijing, Shanghai, but there was still a gap about the average consumption and income level, so people prefered to bus. Through price adjustment now, and rail transit has advantages of time-saving and safety, etc, passenger numbers increase[5]. The experience of Wuhan rail transit line 1 can be learned.

Reducing Operational Costs and Exploring External Benfits. To the problems such as big sunk cost and weak profitability, our government should come out preferential policies of subsidies. For example, in the aspect of fixed assets depreciation and tax, our government should give preferential policies, the tax relief imposed on the project imported goods may be provided, a appropriate reduction in the corporate tax on retained earnings. Or perhaps, our government may establish special funds to support urban rail transit projects through collecting taxes in the period of projected operation, which can be used again in other urban rail transit projects[6]. Our government should formulate corresponding financial statements according to the number of passengers by taking rail transit. Then our government may provide proper subsidies to the company carrying out the project, so as to reduce losses.

\section{Summary}

The constructions of urban rail transit have significant influence on economic and social property, the constructions of urban rail transit success or not in relation to project mode. Aiming at the application problems on BOT mode about urban rail transit project, the problems analysis and solution have very important realistic meaning for development and construction of infrastructure projects.

\section{References}

[1] S.H. Ding, J.Z. ye and Y.J. Ning: Journal of Zhejiang Transportation Science \& Technology, Vol.13 (2008) No.1, p.58-61.

[2] Y.S. Lin: Economic Vision, Vol.13 (2014) No.6, p.26-29.

[3] J.F. Wei: Financing Mode Selection of Wuhan Urban Rail Transit (MS., Wuhan University of Technology, China 2012), p.1-6.

[4] H.W. Yu and C.L. Zhu: Technology and Market, Vol.12 (2012) No.4, p.272-274.

[5] W.L. He: Judicature of China, Vol.8 (2003) No.12, p.66-69.

[6] Y. Liu: Xiamen Science \& Technology, (2001) No.2, p.57-62. 